\title{
SUSTAINABILITY ASSESSMENT OF EXTENSIVE CATTLE AND SHEEP PRODUCTION SYSTEMS IN SOUTHERN CHILE
}

\author{
Juan P. Avilez ${ }^{1 a}$, José Nahed ${ }^{2}$, Yolanda Mena ${ }^{3}$, Daniel Grande ${ }^{4 *}$, Francisco A. Ruiz ${ }^{5}$, José A. \\ Camúñez ${ }^{6}$, Jorge Meyer ${ }^{1 b}$, and José M. Castel ${ }^{7}$
}

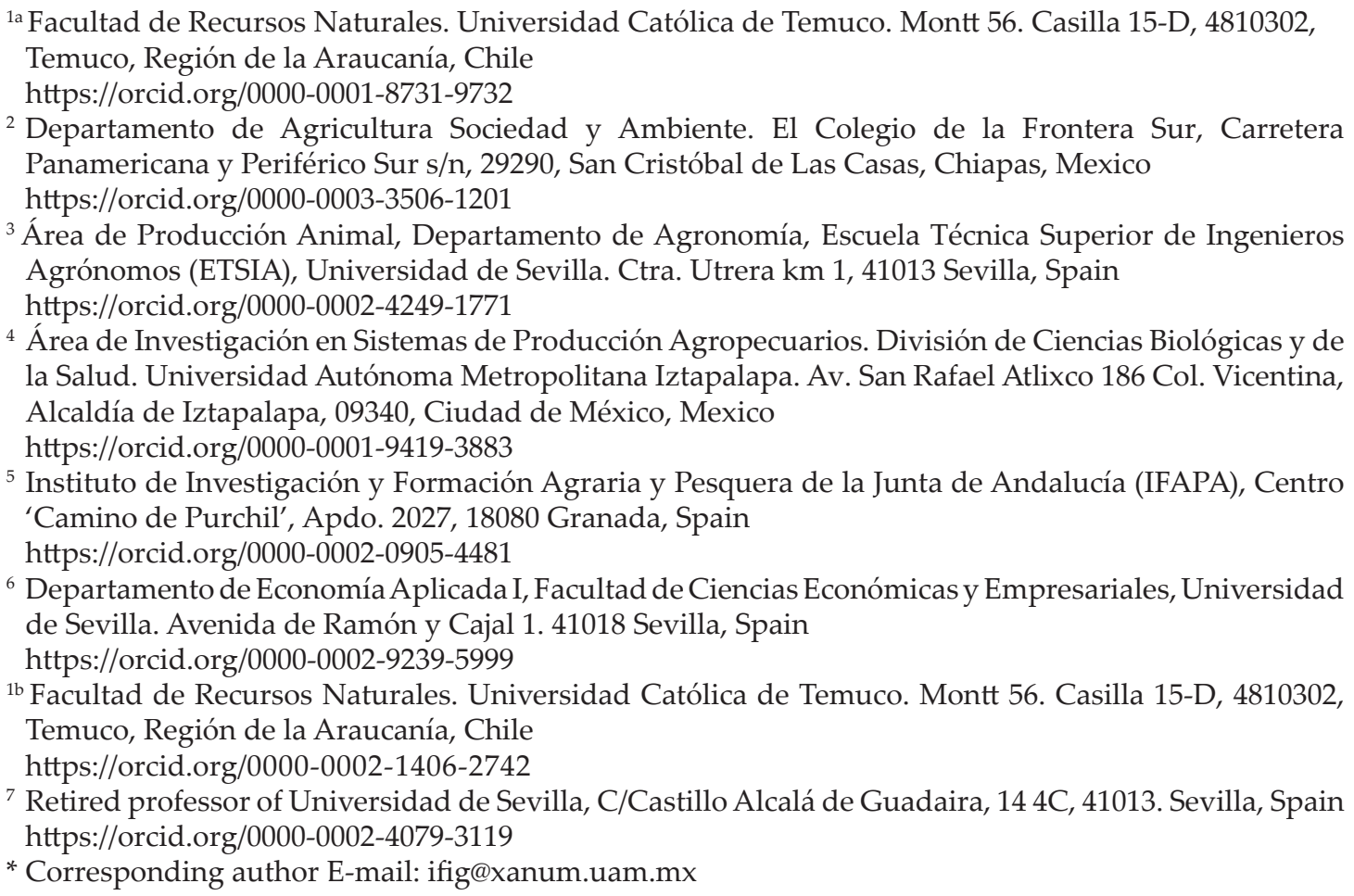

\section{ABSTRACT}

Extensive livestock systems have decreased in the last decades. In general, these systems are characterized by low profitability, but they have a key role on environment conservation, maintenance of rural population, and health of meat and milk consumers. The present study was carried out in 2017 with 29 livestock farmers in the cold steppe area, Rio Ibáñez District (Comuna de Rio Ibánez), Aysén Region, Chile. The objective of this work was to compare the characteristics of extensive cattle and sheep farms of Southern Chile with a previous study conducted in 2012, assess their sustainability in 2017 and propose improvement actions. The variables studied were included in five attributes according to MESMIS methodology: Productivity, Stability, Adaptability, Equity and Self-management. There were few and circumstantial changes between 2012 and 2017. The global sustainability index was calculated $(58 \%)$. The values of the five sustainability attributes were 54-64\%. The results indicate that livestock farmers carry out valuable practices for sustainability, such as Cattle carry out short seasonal migration, Farmer vaccinates animals, Farmer desparasites 
animals, Does soil analyses and Farmer has done training courses. The suggested actions to improve sustainability are related to farm and farmer's characteristics, including trading through farmers' associations and off-farm activities. Collaborative work between livestock farmers and government institutions is required to implement the proposed actions. It is also important to raise consumers' awareness of the importance of extensive production systems and the differentiated quality of their products.

Key words: Sustainability attributes, MESMIS, grazing, farm management, farmer's characteristics.

\section{INTRODUCTION}

Livestock produces leather, wool, manure and high-quality food. However, it is partially responsible for the deterioration of the environment, particularly deforestation and climate change, accounting for around $14.5 \%$ of anthropogenic global greenhouse gas (GHG) emissions. In particular, beef production accounts for $41 \%$ of total emissions from the livestock sector (Gerber et al., 2013).

During recent decades, livestock production has become more intensive and specialized worldwide. This has raised concerns in society due to its high dependence on fossil fuels and agrochemicals, with destruction of natural habitats and ecosystems, environmental pollution and risks for human health (Rigby et al., 2001; ten Napel et al., 2011; Valdivieso et al., 2019). Nevertheless, pasture-based livestock farming and extensive livestock systems are still important (Bernués et al., 2011). In fact, they help prevent depopulation of many marginal areas that are not suitable for cultivation (Bernués, 2011; Bedoin and Kristensen, 2013; Kamilaris et al., 2020). Likewise, livestock production has some beneficial effects on the environment since pastures are a sink of $\mathrm{CO} 2$ and grazing contributes to the balance of ecosystems. Additionally, numerous authors have demonstrated the health benefits attributed to moderate consumption of grass-fed animal products compared to concentrate-fed animals (Bernués, 2011; Kamilaris et al., 2020).

Production of ruminant meat should ideally be based on pastoral systems using low external inputs, considering food security and resulting in positive externalities. Profitability of this type of production can be enhanced through highvalue niche markets (Toro-Mujica et al., 2019). However, although extensive livestock systems generally have a better environmental behaviour than intensive systems, their profitability is quite low (Bernués et al., 2011, 2018; Tessema et al., 2014; Niamir-Fuller, 2016), particularly in small farms (Avilez et al., 2018). Extensive farms are frequently meat-aptitude, but they can also be double-aptitude (meat/wool or meat/milk), and one of the main causes of their low profitability is that weaned rather than fattened animals are produced. This is common worldwide because fattening management only exists in areas and seasons that guarantee sufficient pasture quality and availability, which means it might not apply to drier regions or areas where pastures are scarce or not available (Bernués et al., 2011; Horcada-Ibáñez et al., 2016). At a global scale, the most widely used intensive production system is intensive calf fattening (feedlots) (Bernués et al., 2011; Aguilar et al., 2014; Avilez et al., 2018). Meat produced from grazing animals is based on rustic breeds with lower productivity compared to intensive systems, while meat quality does not satisfy the requirements of the industry (Bedoin and Kristensen, 2013). Therefore, it needs to be commercialized through specific channels aimed at consumers who value different aspects: it is darker with more subcutaneous fat and a characteristic flavor; and it has a higher content of polyunsaturated fatty acids than meat produced only with concentrates and straw (Horcada-Ibáñez et al., 2016). Other aspects such as animal welfare, grazing in non-competitive areas for agriculture, environment conservation, maintenance of rural communities, landscape and biodiversity should also be considered as well as cultural implications and the perspective of cattle production as farmers' saving source (Bernués et al., 2011; Bedoin and Kristensen, 2013; GarcíaMartínez et al., 2011; Horcada-Ibáñez et al., 2016; Nahed et al., 2018). Knowledge about the impact of production methods on the environment, animal welfare, and human health positively affect consumer buying behavior in favor of pasture-raised products (Morales-Jerrett et al., 2020; Stampa et al., 2020). Extensive livestock systems have low production costs, but their sustainability and/or continuity is difficult due to their low levels of productivity. Furthermore, the commercialization strategies used do not ensure adequate prices for consumers, who do not value the special characteristics of extensive livestock products.

Most beef production in Southern Chile is extensive, relying on native and sown pastures and cereal stubbles. Strong seasonality of forage production forces producers to supplement 
animals with alfalfa or red clover hay, and wheat straw (Toro-Mujica et al., 2019). An earlier study conducted by Avilez et al. (2018) characterized extensive, grazing-based cattle and sheep production systems in marginal areas of southern Chile. These systems present medium-low use of external resources, which favors sustainability. However, there are deficiencies, which directly or indirectly affect sustainability. They have deficiencies in farm management, training of livestock farmers and commercialization of products. Therefore, the objective of this work was to analyze the evolution of the characteristics of extensive ruminant (cattle and sheep) farms in southern Chile, assess their sustainability and suggest improvement actions.

\section{MATERIAL AND METHODS}

\section{Area of study}

The present study was carried out in the Río Ibáñez district, Aysén Region, Chile $\left(48^{\circ} 16^{\prime} 00^{\prime \prime} \mathrm{S}\right.$, $71^{\circ} 56^{\prime} 00^{\prime \prime} \mathrm{W}$ ) (Avilez et al., 2018. The study region is cold steppe, with an average temperature 6.4 ${ }^{\circ} \mathrm{C}$ and precipitation of $612 \mathrm{~mm}$; less than $50 \%$ of the rain falls during the period of greatest pasture growth, which goes from September to April (Dirección Meteorológica de Chile, 2020). The minimum temperature can fall to $-37{ }^{\circ} \mathrm{C}$. The soils have a clay loam texture with a $\mathrm{pH}$ greater than 6, low $\mathrm{Al}$ saturation and little presence of sulfur. There are areas of shrubs such as ñire (Nothofagus spp) (57 ha in average), and pastures of low forage value called coirón (Festuca gracillima) where grasses predominate (especially Stipa spp and Festuca pallens) (Demanet, 2017). The predominant sheep breed is Corriedale, of double aptitude (meat and wool), which has been frequently crossed with breeds of early growth. The bovine breeds are of meat aptitude (breeds of British origin) or double aptitude (Overo Colorado), which have been selected during decades for meat production (Hepp et al., 2018). During the summer, the herds carry out a short migration (maximum $10 \mathrm{~km}$ ) towards the areas with better pastures (Avilez et al., 2018).

\section{Farm selected and data collection}

The present study was carried out with livestock farmers who participated in an earlier study carried out in 2012 (Avilez et al., 2018). The farmers actively participated in the characterization carried out in 2012, by giving their opinions on the most relevant aspects of the system, and in the selection of the variables and their subsequent inclusion in the attributes for the sustainability analysis conducted in 2017. From the 227 farms of Río Ibáñez having between 20 and 1000 ha and a bovine herd in the last oficial census (INE, 2007), 29 farms were studied (13\%); all of the farmers belonged to the Bajada Ibáñez Farmers' Association. In the former study (2012) four clusters were found: C1, $\mathrm{C} 2, \mathrm{C} 3$ and $\mathrm{C} 4$, containing 5, 11, 5 and 7 farms, respectively. Between 2012 and 2017, three farms left the association, while four new farms became members.

In the present study, 61 variables were studied, of which 25 were qualitative and 36 quantitative. All the qualitative ones are binary $(0,1)$, except for three that have several options. Qualitative and quantitative variables were selected to evaluate the technological, environmental, economic, and social aspects of a system as previously defined by other authors (Mena et al., 2012; Nahed et al., 2018), and considering farmers' interests and opinions. The variables were grouped into two groups: 20 variables that did not form part of the sustainability analysis (Table 1 ), and 41 variables that accounted for sustainability (Tables 2-6). The variables that best suited each attribute were selected; a score was given to each option if there was more than one, with special care of avoiding duplication of the information.

\section{Sustainability analysis}

The sustainability of farms in 2017 was evaluated using the MESMIS methodology (Masera et al., 1999; Astier et al., 2008), which defines seven attributes for sustainability. According to the adaptation by Nahed et al. (2006), the attributes Reliability, Resilience and Stability were grouped and named Stability, and thus only five attributes were used. The value of each of the five attributes was determined by the values of several variables; the final value of each attribute was the average of its unweighted variables. The 41 variables accounting for sustainability were distributed as follows: Productivity attribute (6 variables), Stability (10 variables), Adaptability (10 variables), Equity (6 variables), and Selfmanagement (9 variables). Some variables may belong to more than one attribute. However, they were assigned to just one each according to the authors' judgement (Nahed et al., 2006).

The value for each sustainability attribute was expressed as a percentage. These values defined the relative importance of each attribute in explaining the sustainability of the system; the higher the value of the attributes, the higher the level of sustainability. Subsequently, each of the variables was compared to an optimal reference value (desirable value for each variable, achievable in an ideal system), independent of their original unit (Arnés et al., 2013). The values of the variables were adapted to a new scale of $0-100 \%$, with $100 \%$ 
being the highest sustainability value (optimal value) and $0 \%$ the lowest. The criterion for the definition of the optimal value of each indicator was mainly based on the minimum or maximum absolute value obtained from the sample of farms studied. In some cases, the optimal value was taken as the maximum or minimum value of the means of the systems (Nahed et al., 2006). This was because the authors considered that in these cases, the maximum or minimum value was not representative as the optimal value for the farms in the study area. The variables and their descriptions, results and optimal reference values are shown in Tables 2-6. A sustainability index (SI) was calculated as proposed in other works (Rigby et al., 2001; Nahed et al., 2006). The value of the SI obtained in this study for each farm was expressed as a percentage representing the arithmetical average of the values of the five sustainability attributes.

\section{Statistical analysis}

The situation in 2012 was compared with that in 2017 using for the quantitative variables: a Student's t-test for independent samples between the values of the variables for those two years, and a Chi-square of Pearson test for the qualitative variables (Tables 1-6). For the 2017 data, a Chi-square of Pearson test was also used to obtain the significant differences in some important quantitative variables with respect to some qualitative variables (Table 7). All the statistical analyses were carried out with the IBM SPSS Statistics 20 statistical program.

\section{RESULTS}

Tables 1-6 show the results of the Student's t-test for independent samples between the 2012 and 2017 values for the quantitative variables, and the Chi-square test for the qualitative variables. Tables 2-6 show the sustainability analysis of the five attributes studied, including the optimal value for each attribute and the values of the variables accounting for each of the sustainability indicators compared with the optimal values or ideal point.

In the attribute Productivity (Table 2), there are significant differences between 2012 and 2017 for the variable Feed cost per Livestock Unit (LU). There are no significant differences between 2012 and 2017 for any of the variables in the attribute Stability (Table 3). The variables in the attribute Adaptability present similar values between 2012 and 2017, except for three variables related to management and one associated with assistance. (Table 4). In the attribute Equity, there is only one variable with significant differences between 2012 and 2017: Farmer has done training courses (the value has increased) (Table 5). In Self-management, there are significant differences between 2012 and 2017 for three variables, increasing for Bales of hay $(25 \mathrm{~kg}$ ) purchased per LU and year and Keeps production records, and decreasing for the variable Trading even through an association (Table 6).

Table 7 shows the results of the quantitative variables that present significant differences with respect to different qualitative binary variables according to T-Student's Test (Hired labor, Owner of the territorial base, Woman living alone and High education. When the presence of Hired labor is compared to no hired labor, the average size of the farms as well as the expenses are almost triple, and both income and Profit double. When the Farmer is the Owner of the territorial base, $70 \%$ more concentrate is supplied to the animals. When the Woman runs the farm, the average amount of hay purchased is much higher than the rest of the cases ( 0.9 vs 5.9 bales per LU) and the Feed cost per $L U$ is multiplied by three. Finally, there is a positive and significant relationship between farmer's youth and high level of education.

The mean sustainability value for the five attributes was $58 \%$, indicating that sustainability of the sample (farms) assessed was medium. The highest sustainability values were for the attributes of Productivity and Self-management (62\% and 64\%, respectively). For the other three attributes, the sustainability index was lower than $60 \%$. In the different sustainability attributes, eight variables present proximity of $90 \%$ or more to the optimal value. Results indicate that livestock farmers carry out valuable practices: Cattle carry out short seasonal migration, Farmer vaccinates animals, Farmer desparasites animals and Does soil analyses, as well as receiving training: Farmer has done training courses.

\section{DISCUSSION}

Firstly, each sustainability attribute and the sustainability index are discussed. Secondly, some actions, which involve different variables and can affect multiple attributes, are suggested to improve sustainability of the farms assessed.

\section{Sustainability attributes and Sustainability index \\ Productivity attribute}

The mean value of the Productivity is medium-high (62\%). The variables furthest from the optimal value are Feed costs per LU and Sold lamb incomes. The Productivity value is similar to that observed in extensive sheep or cattle farms in Extremadura (Spain) (Franco et al., 2012) (Table 8), but it is much higher than in 
Table 1. Variables not included in the sustainability attributes (mean and standard error or frequency) in 2012 and $2017^{+}$.

\begin{tabular}{|c|c|c|c|c|c|}
\hline Variables & 2012 & 2017 & Variables & 2012 & 2017 \\
\hline № of farms & 28 & 29 & & 28 & 29 \\
\hline Person in charge of the farm: & & & № of ewes \#\# & $32( \pm 7)$ & $55( \pm 25)$ \\
\hline Woman living alone (\%) & 39 & 34 & Total Livestock Units (LU) & $30( \pm 4)$ & $38( \pm 5)$ \\
\hline Husband runs the farm (\%) & 46 & 59 & Concentrate cost (€/year) & $220( \pm 35)$ & $245( \pm 35)$ \\
\hline Wife runs the farm (\%) \# & 14 & 7 & Farm hay cost (€/year) & $1056( \pm 282)$ & $514( \pm 197)$ \\
\hline Territorial Base & & & Total feed cost (€/year) & $1275( \pm 300)$ & $759( \pm 217)$ \\
\hline Owned (\%) & 64 & 66 & Rented cost (€/year) & $35( \pm 35)$ & $31( \pm 31)$ \\
\hline Rented (\%) & 4 & 3 & Hired labor cost (€/year) & $732( \pm 303)$ & $601( \pm 223)$ \\
\hline Belonging to the family group (\%) & 18 & 17 & Medication cost (€/year) & $49( \pm 19)$ & $57( \pm 18)$ \\
\hline Inheritance process (\%) & 14 & 14 & Total costs (€/year) & $2092( \pm 411)$ & $1447( \pm 306)$ \\
\hline Water available: & & & № calves sold per cow \#\#\# & $0.76( \pm 0.05)$ & $0.72( \pm 0.04)$ \\
\hline Well (\%) & 25 & 17 & № lambs sold per ewe ${ }^{* * \# \#}$ & $0.35( \pm 0.04)$ & $0.42( \pm 0.03)$ \\
\hline Mains (drinking water) $(\%)$ & 7 & 7 & Total sales (€/year) & $9399( \pm 1533)$ & $12404( \pm 1887)$ \\
\hline Spring, river or lake $(\%)$ & 68 & 76 & T. costs per LU (€/year)* & $70( \pm 6)$ & $36( \pm 7)$ \\
\hline Total farm area (ha) & $257( \pm 56)$ & $287( \pm 60)$ & T. sales per LU (€/year) & $296( \pm 21)$ & $331( \pm 16)$ \\
\hline Grazing area (ha) & $209( \pm 49)$ & $230( \pm 51)$ & Profit per LU (€/year)* & $226( \pm 25)$ & $296( \pm 18)$ \\
\hline
\end{tabular}

+ Significant differences between 2012 and 2017 values are indicate by ${ }^{*}$ or ${ }^{* *}\left({ }^{*}=p<0.05 ;{ }^{* *}=p<0.01\right)$.

\# Husband works in mining; \#\# Only farms with sheep; \#\#The animals are always sold after weaning.

conventional cattle production units in Chiapas (Mexico). In this sense, Nahed et al. (2018) reported a $38 \%$ Productivity because production cost was high, while animal production in the study area relies on scarce food supplement. In semi-extensive Spanish dairy goat production, Productivity value is also higher $(76 \%)$ because the results obtained by Nahed et al. (2006) show that spending on food that complements grazing has a good impact on the level of production obtained. Similarly, a study conducted in the Pampa Biome (Brazil) by da Silveira et al. (2019) reported a higher Productivity value than that of the present study; farm profitability in this Brazilian area increased from the expansion of soybean cultivation, combined with cattle raising. The variable Feed cost per LU in 2017 was lower than in 2012. Although the total rainfall in the study area was similar in 2012 and in 2017 (650 vs. $669 \mathrm{~mm}$ ), it was much better distributed in 2017; while there was heavy rain only in May and June of 2012, it was relatively abundant for most of the period from January to August of 2017 (Gobierno de Chile, 2017). The Aysén Region has a cold climate that makes grass production very seasonal; in autumn-winter (from September/ October to March/April), the grass goes into dormancy. In summer, the limiting factor is the lack of humidity, which is more drastic than in the so-called wet Patagonia, located about $100 \mathrm{~km}$ from the study area (Hepp et al., 2018; Reyes et al., 2020).

\section{Stability attribute}

Farm size is particularly important for the resilience value because profitability of small farms is very low and this may compromise their future (Avilez et al., 2018). Regarding farm size, Stocking rate is another important variable for the resilience of the pasture-based farms. It is higher (0.6 LU/ha) than that of other extensive livestock farming systems in Spain (Franco et al., 2012; Ripoll-Bosch et al., 2012). However, it is similar to that of pastoral beef production systems and cattle and sheep pasture systems of Southern Chile (Toro-Mujica et al., 2019; Avilez et al., 2018), and lower than that of other livestock farming systems in the State of Veracruz, Mexico (around 1 LU/ha) (Chalate-Molina et al., 2010). The Farm profit in 2017 was $10957 €$.

Considering that median household expenses in Chilean cities were $15936 €$ (INE, 2017) and the lowest needs in rural areas, this Farm profit can be considered acceptable for a decent life. However, according to Avilez et al. (2018), $40 \%$ of the farms in the study area have around half (or less) the average of Farm profit.

The value of the Stability attribute in this study is medium (55\%) (Table 3). The main variables contributing to sustainability are Territorial Base, Electricity and facility availability and Number of cows. The value of this attribute is lower than the value for the conventional cattle production units $(64 \%)$ in Chiapas (Mexico) as reported by Nahed et al. (2018). According to the authors, some 

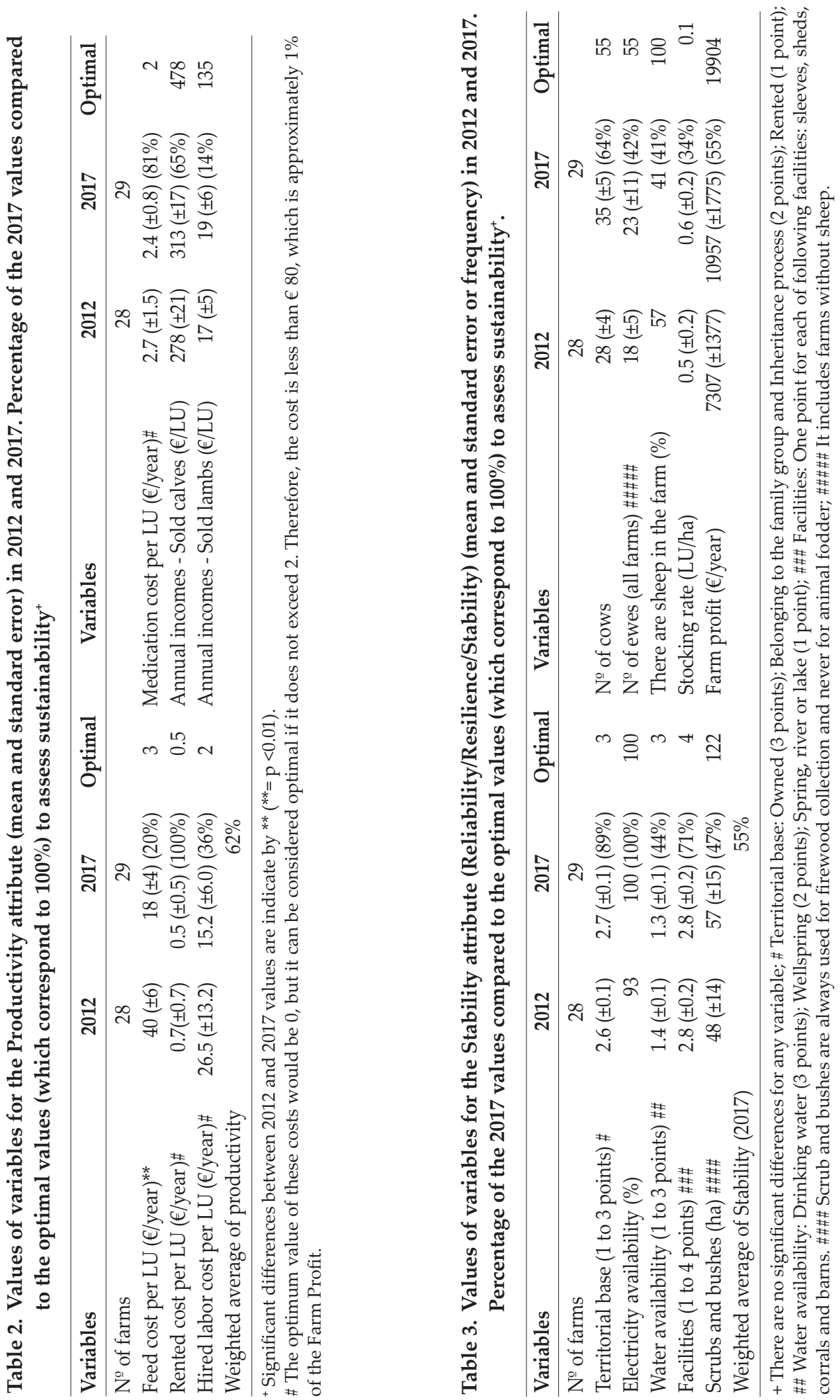

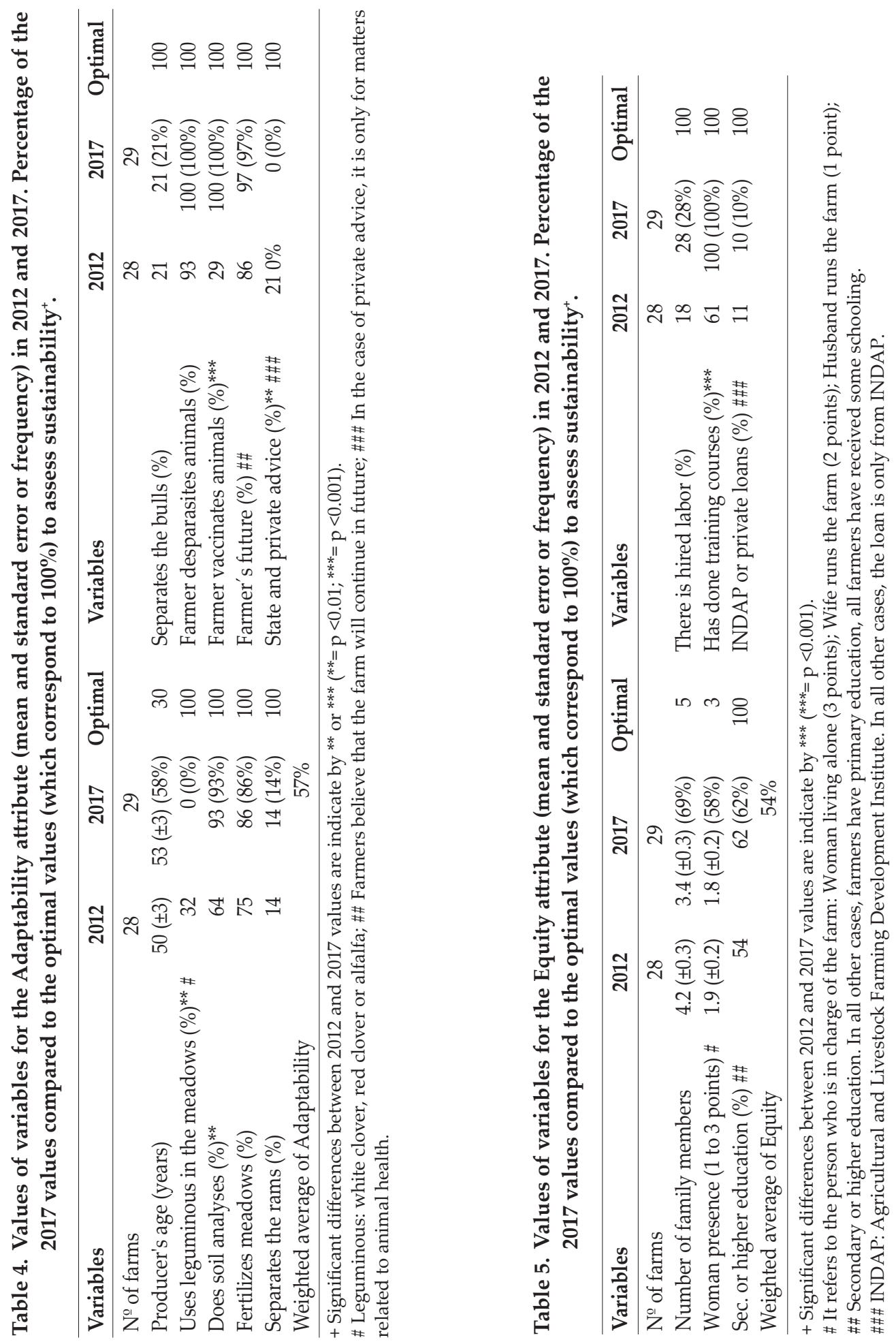


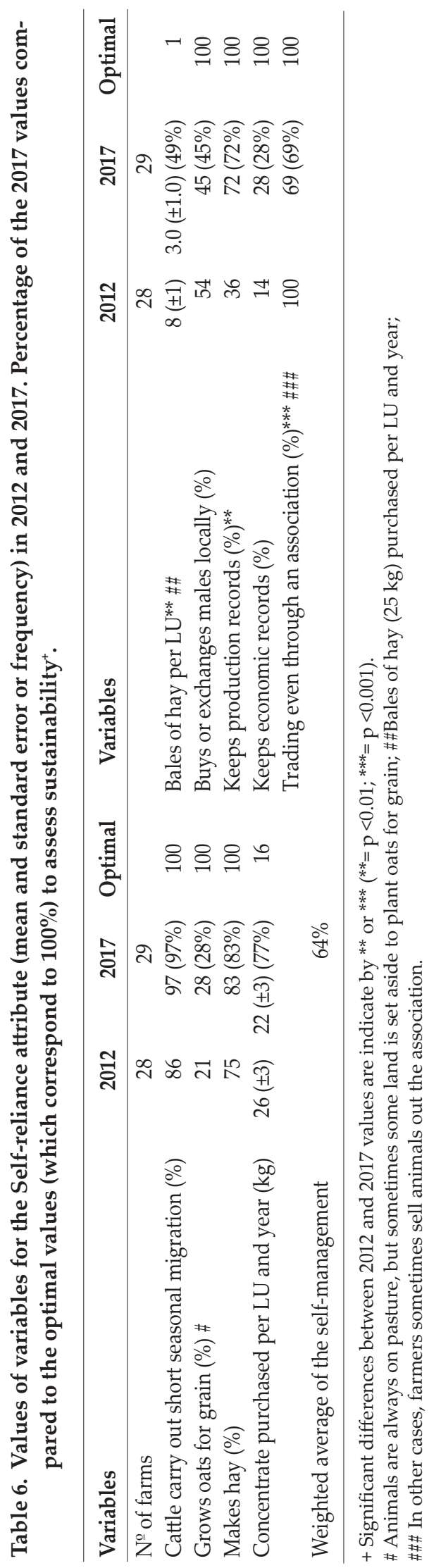

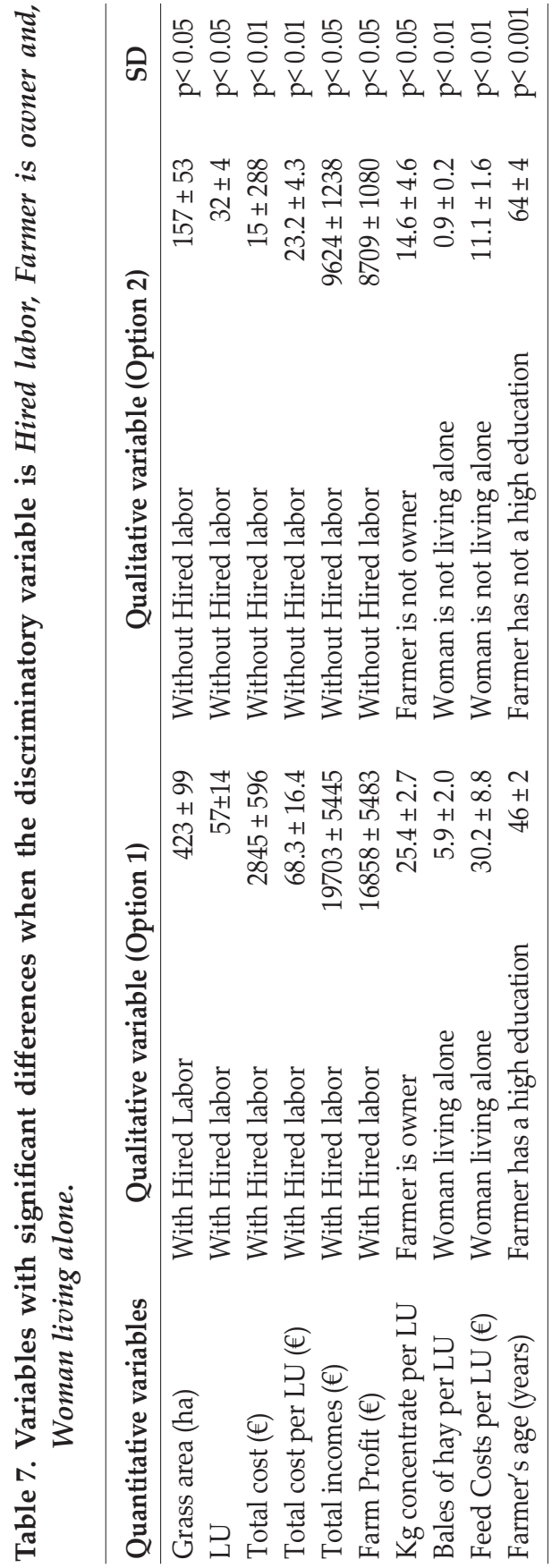

variables were placed in a different attribute and those that contributed the most to raising the value of this attribute were those related to the use of fertilizers and herbicides in pastures, calf mortality rate and sale price of milk. A higher Stability value of $63 \%$ was reported for extensive sheep or cattle farms in Extremadura (Spain) (Franco et al., 2012), which can be explained by a lower Stoking rate value ( $0.3 \mathrm{LU} / \mathrm{ha})$ compared to 
Table 8. Comparison of attribute values (\%) and sustainability index with other studies.

\begin{tabular}{lcccccc}
\hline Studies & Productivity & Stability & Adaptability & Equity & Self-management & $\begin{array}{c}\text { Sustainability } \\
\text { Index }\end{array}$ \\
\hline Current study & 62 & 55 & 57 & 54 & 64 & 58 \\
Nahed et al. (2006) + & 76 & 43 & 58 & 49 & 61 & 57 \\
Franco et al. (2012)++ & 66 & 63 & 53 & 47 & 76 & 59 \\
Nahed et al. (2018)+++ & 38 & 64 & 45 & 32 & 79 & 52 \\
da Silveira et al. (2019)++++ & 70 & 48 & 18 & 84 & 36 & 51 \\
\hline
\end{tabular}

+ Semi-extensive Spanish dairy goat production.

++ Extensive sheep or cattle farms in Extremadura (Spain).

+++ Conventional cattle production units in Chiapas (Mexico).

++++ The most sustainable livestock production systems in the Pampa biome of Río Grande do Sul state (Brazil).

that in our study area. Conversely, the Stability value in the current study is higher than that in Spanish dairy goat production (43\%). This is because dairy systems are more complex, and therefore their stability depends on many more variables (Nahed et al., 2006). The Stability attribute in the Pampa Biome (Brazil) (da Silveira et al., 2019) is lower, while the variables that mostly contribute to a medium value are those related to farm size (area and animals) and maintenance of native vegetation.

\section{Adaptability attribute}

Some variables associated with this attribute are related to crop management and largely depend on government financial support. This is also observed in the case of health practices with livestock (INDAP, 2014 Avilez et al., 2018). Government policies have changed in recent years, promoting the use of some practices but not others (Table 4). As with many extensive livestock farming systems, there are deficiencies in reproductive management and sowing to obtain hay or grain (Avilez et al., 2018; Ruiz et al., 2020). Such variables can account for both Adaptability and Self-reliance; in the present study, they were included in Self-reliance. In 2012, Farmer advice to all the farms was provided by government institutions, complemented by some private visits (intended only for animal health matters). The cost of private veterinary assistance is regulated by the Veterinary Medical Association, and is approximately 120 euros per visit, $60 \%$ of which correspond to travel costs because distances are usually long. In 2017, no private assistance was given in any of the farms. Private assistance varies depending on the evolution of sale prices of the animals, and therefore on the farmer's income, being part of the Adaptability process.

The Adaptability index obtained in the present study is medium (57\%) (Table 4), and agrees with values reported in Spanish dairy goat production (58\%) (Nahed et al., 2006), and extensive sheep or cattle farming (53\%) in Extremadura (Spain) (Franco et al., 2012). However, it is much higher than that in conventional cattle production units $(45 \%)$ in Chiapas (Mexico) as reported by Nahed et al. (2018) who stated than Adaptability was generally low because the producers have little capacity for change and innovation, receive little technical assistance and have a low level of education. In addition, the low productivity of the farms leads to low economic reinvestment. Furthermore, Adaptability attribute in the present study is also higher than that found by da Silveira et al. (2019), who reported a very low value because they only included variables that are not very developed in the area, such as farmers' education, training and association capacity.

\section{Equity attribute}

In the Equity attribute, variables related to education, workforce and gender. In terms of education, $62 \%$ of farmers have a high level of education in the present study. According to the study of Avilez et al. (2018), it is encouraging to see that there are young farmers ( $39 \mathrm{yr}$ old average) with a high level of education $(82 \%)$ in the cluster that includes the greatest number of farms. In many cattle production areas in Latin America, such as Veracruz and Morelos (Mexico), the level of education of farmers is low, and around $80 \%$ of them only have primary education (Chalate-Molina et al., 2010).

Presence of Women is higher in the study area ( $41 \%$ of farms are run by a woman alone or run by a woman whose husband works off farm) than in other parts of Latin America, with the exception of goat's milk farmers of Cuenca (Peru), where the situation is similar (Sarria et al., 2014). This is due to the fact that there is work in the mines, and recently in fishing factories and tourism. 
In the current study, Hired Labor is only found in big farms (Table 7). In rural areas, there are increasing labor problems due to hard work and job opportunities for young people in other sectors. On the one hand, these off-farm activities complement the family economy, but sometimes they represent competition for the labor force (García-Martínez et al., 2011).

The mean value of the Equity attribute for all the farms was $55 \%$ (Table 5), being a little higher than that in Spanish dairy goat production (49\%) (Nahed et al., 2006), and in extensive sheep or cattle farms $(47 \%)$ in Extremadura (Spain) (Franco et al., 2012), while it is much higher than in conventional cattle production units $(32 \%)$ in Chiapas (Mexico) (Nahed et al., 2018). The value of the Equity attribute reported by da Silveira et al. (2019) in the Pampa Biome (Brazil) is very high (68.8-84.1\%). The authors included variables of very different nature in this attribute (management, conservation of natural resources, grazing, etc.), which makes it difficult to compare the results.

All variables integrated in the Equity attribute have values higher than $50 \%$, except the presence of Hired labor and Bank loans for farmers. Nahed et al. (2018) reported a very low value for Hired labor and Presence of women in farm decision making.

\section{Self-reliance attribute}

Regarding variables included in the self-reliance attribute, most livestock farmers use seasonal migration of the livestock, which is a good practice for solving forage shortages in critical seasons, also used in other extensive livestock farming systems (Bernués et al., 2011; Avilez et al., 2018; Ruiz et al., 2020). In contrast, few livestock farmers (28\%) grow oats for grain or keep economic records (28\%) (Table 6). Although $83 \%$ of farmers produce hay, the amount produced is not enough, and therefore they must buy 3 bales per LU every year. This can be explained by the difficulty of growing crops in marginal zones as reported by other authors (Ruiz et al., 2020), decreasing Self-reliance (RipollBosch et al., 2012). A 31\% of the farmers sold part of the production without participation in farmers' associations. This indicates that negotiation of sale prices by an association is not positively evaluated (Avilez et al., 2018). However, participating in such associations gives access to information/ knowledge and innovation, improving autonomy.

The weighted mean of the Self-management attribute of all the farms was $61 \%$, (mediumhigh), which is similar to that in Spanish dairy goat production (64\%) (Nahed et al., 2006), but lower than in conventional cattle production units $(79 \%)$ in Chiapas (Mexico) (Nahed et al., 2018) and in the extensive sheep or cattle farms (76\%) in Extremadura (Spain) (Franco et al. 2012). In the case of conventional cattle production units in Chiapas (Mexico), there is a very low dependence on external feed. However, production costs are high because of the costs of medicines and Hired labor as well as part of the agricultural costs since livestock and crops are integrated in the farming system. Nevertheless, the Self-reliance attribute in soybean cultivation in the Pampa Biome (Brazil) (da Silveira et al., 2019) is lower because the soybean cultivation is related to high indebtedness due to the need for investments and the use for external inputs. In addition, pastures for Livestock can only be used in winter, since they are occupied by soybean cultivation in summer, resulting in an increase in purchased feed for livestock.

\section{Global sustainability}

The Sustainability index in the study area is $58 \%$, a medium value that agrees with other studies (Nahed et al., 2006; Franco et al., 2012). However, the values of the different attributes do not vary significantly between them, which differs from those studies, ranging between $54 \%$ in Equity and $64 \%$ in Self-reliance (Table 8 ).

There are multiple synergies and trade-offs between the different attributes (e.g., efficiency and adaptability; productivity and self-reliance) (Ripoll-Bosch et al., 2012). For this reason, livestock farming must be analyzed considering all aspects of sustainability (Bernués et al., 2011).

\section{Possible actions to improve sustainability}

Actions are proposed for some aspects of the production system based on all the attributes analyzed. They can affect more than one attribute, or even have a negative impact. Therefore, before making any change, it is necessary to study its feasibility and possible effects. In this sense, it is expected that the results will be jointly analyzed by farmers, technicians, sociologists, economists and government agents.

\section{Actions concerning animal and territorial base, farm management and infrastructures and facilities \\ There is presence of cattle in all of the farms, but} sheep are found in only $41 \%$ of them. Compared to single species grazing, more than one species of animals use vegetation resources more efficiently and biodiversity increases (Bernués et al., 2011; Mena et al., 2016; Ruiz et al., 2020). At the same time, there is a better distribution of tasks throughout the year and a diversification of income. All of this can enhance Stability and Equity attributes. Likewise, around 57 ha of scrubs and bushes in the study area could be used by goats. Goat cattle are currently produced in marginal areas of other 
areas of the Río-Ibáñez District. Like sheep, goats are partly used for self-consumption, while sales are informal and seasonal. Concerning herd size, there is no benefit in increasing Stocking rate, except in some big farms. If LU increased in large farms (having sufficient Hired labor in general), the Costs per LU could decrease, increasing Productivity.

Concerning farm management, a strategy to overcome the lack of pasture is to manage reproduction so as to adapt the animals' greatest nutritional requirements to the season when most natural pasture is available (Reyes et al., 2020; Ruiz et al., 2020). This involves controlling mating periods by separating males from females (Avilez et al., 2018). With the improvement of soils, the production of grain and hay in marginal areas could be increased (more Self-reliance and Productivity) (Demanet, 2017; Toro-Mujica et al., 2019; Reyes et al., 2020; Ruiz et al., 2020). The sowing of legumes for the improvement of pastures is very changeable from one year to another and depends on Government policy (Table 4). On the other hand, apart from working on improving nutrition and reproduction, it is important to raise breeds that fit the suggested actions for improvement (Iñiguez, 2011; Kamilaris et al., 2020).

Overall, excessive expenses or investments should be avoided in extensive farms because profit is low, and it is also difficult for farmers to obtain loans. In fact, only $10 \%$ of farmers have access to bank loans in the study area. This is evidence of the existence of trade-offs between Productivity and Adaptability (Ripoll-Bosch et al., 2012).

Steer fattening cannot be conducted in the study area due to rain scarcity and poor quality of grasses. For this reason, farmers can obtain more income either by obtaining better sales prices for weaned calves or by participating in the fattening process: (i) intensive fattening on the farm itself or, collectively, on leased farms; (ii) organize themselves in associations to carry out fattening in other areas with good pastures, supplying the minimum possible quantity of concentrate.

Although many farmers put the farming lifestyle as being more important than profits, a minimum productivity is essential for the continuity of productive systems (Bernués et al., 2011). According to the present study, most farmers agree that livestock activity will continue in the future (Table 4). However, many young people try to work in the growing tourism and fishing sectors (Díaz et al., 2011).

In relation to infrastructure, Water availability is the variable with the lower value since only $7 \%$ of farms have drinking water. Therefore, this aspect must be addressed as a priority. For grazing improvement, aspects such as drinking points, shelters, and the use of GPS tracking should be considered (Ruiz et al., 2020). Investments in infrastructure or facilities lead to a greater Adaptability (Nahed et al., 2006). Improving these variables, which are included in the Stability attribute, requires investment but it would also help improve both livestock and people welfare, and it could indirectly have a positive effect on Productivity.

\section{Actions concerning farmer's characteristics, Associations and Off-farm activities}

The fact that Owner farmers supply more concentrate to the livestock than those who do not own the farm (Table 7) indicates a greater interest in obtaining good Productivity, even if profits do not vary significantly. On the other hand, the positive relationship between youth and high level of education can favor improvement and innovation of production systems (Table 7). Level of education $(62 \%$ of farmers) is higher than that of pastoral farmers in other countries (Avilez et al., 2018). It is also important to encourage Keeping technical-economic records (only $28 \%$ keep economic data), which leads to better Self-reliance. Many of the proposed actions depend on the collaboration capacity of farmers, especially small ones (Schwab et al., 2020). Regarding marketing, associations can be useful for product diversification and niche market orientation (Bernués et al., 2011). To increase the effectiveness of commercialization in the study area, the only existing association needs to become more active, or other associations need to be created (Iñiguez, 2011; Aguilar et al., 2014; Avilez et al., 2018; Ruiz et al., 2020), which would improve Self-reliance and Productivity of the farms.

Another aspect to consider in the study of sustainability is off-farm activities by the farmer or family members, such as producing elaborated products, handicrafts or tourism, which complete the family Farm profit, increasing Stability attribute (Ripoll-Bosch et al., 2012, 2014; Ruiz et al., 2020). The increase of labor enhances Equity. However, livestock activity may decrease in areas where off-farm activities are on the rise (GarcíaMartínez et al., 2011). The increasing importance of tourism and the expansion of salmon farming in Southern Chile have been relevant sources of offfarm employment, particularly for young people (Díaz et al., 2011).

\section{Actions concerning the commercialization}

The income from production can be increased by finishing and processing slaughtered animals (cattle and sheep) and by selling meat. For this, a greater integration of agribusiness and producers is required, particularly in the case of small producers (Hepp et al., 2018; Toro-Mujica et al., 2019). In addition, difficulties in the transportation 
of animals in Chile must be taken into account (Werner et al., 2013). In view of the weakness of markets for the sale of the production of extensive livestock farms (Ripoll-Bosch et al., 2014) and the difficulty of competing with the prices offered by intensive production systems (Niamir-Fuller, 2016), commercial strategies need to be improved, e.g. by selling differentiated quality products, if possible, using short commercial circuits (Avilez et al., 2018).

The comparative advantages and quality of their products need to be demonstrated (HorcadaIbáñez et al., 2016; Nahed et al., 2018; Hepp et al., 2018). Differentiation and quality of extensive livestock should be accredited by brands related to cooperatives, breed associations, PGIs, pastoral production or origin of production area (GómezRamos et al., 2006; Martín-Collado et al., 2014; Ruiz et al., 2020). Hepp et al. (2018) proposed that the meat produced in Aysén should be marketed under the "Patagonia" brand, highlighting that it is produced under clean and natural production systems, based on pasture grazing and with good welfare for animals. As this type of farming is intrinsically organic, product differentiation can also be approached from this aspect. However, it is difficult to obtain food that complies with organic standards, while product commercialization is also a challenge (Mena et al., 2012). Furthermore, quality criteria should be readily available to consumers by providing appropriate labeling in order to promote the consumption of meat produced under pastoral systems in niche markets (García-Martínez et al., 2011; Bedoin and Kristensen, 2013; Tessema et al., 2014)). Different channels can be used to connect with interested consumers, using mass media as radio, or television and the internet. In some cases, the production can be directly sold to restaurants or citizens who need regular supply (Toro-Mujica et al., 2019; Stampa et al., 2020).

If labelling included the characteristics of the products, the farm where they are produced and its level of sustainability, customers would be aware of valuable information. Currently, consumers can access a WEB site with all this information using a mobile phone's QR code reader application (Stampa et al., 2020). Another way of making the information available is through a collective brand, which consists of a participatory differentiating mark designed by the interested parties themselves (producers and consumers) (Gómez-Ramos et al., 2006).

\section{Participation of public institutions in improvement actions}

Some variables for the Equity and Adaptability attributes are particularly influenced by public policies. In Chile, there are state subsidies for soil improvement, but policies can be further enhanced (Díaz et al., 2011; Werner et al., 2013; Demanet, 2017; Toro-Mujica et al., 2019). Government efforts should address technology transfer including training on farm management, and incentives to promote farmers' associations (Gómez-Ramos, 2006; Toro-Mujica et al., 2019; Ruiz et al., 2020). Government institutions should also collaborate in the promotion of products obtained from livestock linked to grazing (Tesssema et al., 2014), which in general are little known by consumers (Morales-Jerrett et al., 2020). The development of off-farm activities also needs government support (Ripoll-Bosch et al., 2012). It is essential to raise consumers' awareness of the role of extensive farming so that prices paid to extensive livestock farmers compensate their provision of environmental services, such as protection of biodiversity, carbon sequestration by pastures and protection against fires (Bernués et al., 2011; Gerber et al., 2013; Morales-Jerrett et al., 2020).

\section{CONCLUSIONS AND IMPLICATIONS}

Maintenance of extensive livestock is difficult because Productivity is low for pastures and medium-low for livestock. In the case of the cold steppe in southern Chile, the long cold period and rain scarcity are important factors so that Farm profit is generally medium-low, and particularly low in the case of smaller farms. The values of the variables analyzed in the present study (conducted in 2017) have slightly changed with respect to the results of the characterization conducted in 2012. Significant differences were found in the following variables: Productivity attribute: Feed cost per LU; Adaptability, three variables related to management and one variable related to assistance; Equity, Farmer has done training courses; and Selfmanagement, Bales of hay purchased per LU, Keeps production records and Trading even through an association. The sustainability of the study area is medium $(58 \%)$, being similar to other ruminant grazing systems. However, all attributes have medium values (more balanced than in other areas). The results indicate that livestock farmers conduct valuable practices for sustainability like Cattle carry out short seasonal migration, Farmer vaccinates animals, Farmer desparasites animals, Does soil analyses and Farmer has done training courses.

For sustainability improvement, the effectiveness of farm management (reproduction and feeding) should be improved. Better commercialization of products is also required. Furthermore, farmers' participation in weaned animal fattening, processing of slaughtered animals 
and even in meat commercialization should also be considered. Improving the variables included in the Stability attribute requires investment, but it would help improve both livestock and people welfare, and it could indirectly have a positive effect on Productivity.

The results obtained by applying the MESMIS methodology allowed identifying the main weaknesses of traditional livestock systems. In this sense, improvement strategies should jointly developed by farmers, technicians, sociologists, economists, and government agents.

The aspects with higher sustainability values should be used to promote the consumption of livestock products, while those with lower values should be improved so that they can also be used for promotion in the future.

\section{ACKNOWLEDGEMENTS}

This work was funded by Innova-CORFO Project 11 NTEC 12793 "NODO RÍO IBÁÑEZ", Aysén Region of Chile. The authors would also like to thank the farmers who took part in the study for their cooperation.

\section{LITERATURE CITED}

Aguilar, J.R., J. Nahed, A. Valdivieso, B. Sánchez, and S.J. Mijangos. 2014. Análisis multidimensional de la ganadería bovina en la cuenca alta y media del río Grijalva. p. 378-405. En: E.M. González, and M.C. Brunel (eds.). Montañas, pueblos y agua: Dimensiones y realidades de la cuenca Grijalva. Juan Pablos editor/ECOSUR. México. Available at https://bibliotecasibe. ecosur.mx/sibe/book/000007365. (Accessed November 8, 2020).

Arnés, E., J. Antonio, E. Del Val, and M. Astier. 2013. Sustainability and climate variability in low-input peasant maize systems in the central Mexican highlands. Agriculture, Ecosystems and Environment 181:195-205. https://dx.doi:10.1016/j.agee.2013.09.022

Astier, M., O. Masera, and Y. Galvan. (Coords). 2008. Evaluación de sustentabilidad. Un enfoque dinámico y multidimensional. SEAE, CIGA, ECOSUR, UNAM, CIE, GITRA, Mundi-Prensa. México. 201 p. Available at https://www.ciga.unam.mx/ publicaciones/index.php/component/abook/ book/12-coleccionesciga/12-evaluacion-desustentabilidad- (Accessed November 5, 2020).
Avilez, J.P., J. Meyer, J. Nahed, F.A. Ruiz, Y. Mena, and J.M. Castel. 2018. Classification, characterisation and strategies for improvement of cattle and sheep pasture systems in marginal areas of Southern Chile. Revista Mexicana de Ciencias Pecuarias 9(2):240-262. https://dx.doi:10.22319/rmcp. v9i2.4491

Bedoin, F., and T. Kristensen. 2013. Sustainability of grassland-based beef production - Case studies of Danish suckler farms. Livestock Science1 58:189-198. https://dx.doi:10.1016/j. livsci.2013.10.006

Bernués, A., R. Ruiz, A. Olaizola, D. Villalba, and I. Casasús. 2011. Sustainability of pasturebased livestock farming systems in the European Mediterranean context: synergies and trade-offs. Livestock Science 139:44-57. https://dx.doi:10.1016/j.livsci.2011.03.018

Bernués, A., T. Rodríguez-Ortega, D. MartínCollado, I. Casasús, and A.M. Olaizola. 2018. Evaluación de sostenibilidad en ovino de carne. p. 29-43. En XLIII Congreso Nacional y XIX Congreso Internacional de la Sociedad Española de Ovinotecnia y Caprinotecnia. SEOC 2018. 19-21 de Septiembre. Zaragoza, España. Sociedad Española de Ovinotecnia y Caprinotecnia, Zaragoza, España. Available at http://hdl.handle.net/10532/4236. (Accessed November 9, 2020).

Chalate-Molina, H., F. Gallardo, P. PérezHernández, F.P. Lang, E. Ortega, and J. Vilaboa. 2010. Características del sistema de producción bovinos de doble propósito en el estado de Morelos, México. Zootecnia Trop 28(3):329-339. http://ve.scielo.org/scielo.php?script=sci arttext\&pid=S0798-72692010000300004. (Accessed November 15, 2020).

da Silveira, C., V.C. Pires, R.C. Coelho, and F.L. Ferreira. 2019. Typology of family livestock production systems in the Pampa biome using the MESMIS method. Semina: Ciências Agrárias, (Londrina) 40(6) Suppl. 2: 3249-3268. https://dx.doi:10.5433/16790359.2019v40n6Supl2p3249

Demanet, R. 2017. Pastizales de Chile Zona templada húmeda fría. Estepa. Praderas y Pasturas. Universidad de la Frontera, Chile. Available at http://www.praderasypasturas. com/new/index.php/catedras/praderas-ypasturas/2017 (Accessed April 22, 2021).

Díaz, G.I., L. Nahuelhual, C. Echeverría, and S. Marín. 2011. Drivers of land abandonment in Southern Chile and implications for landscape planning. Landsc. Urban Plan. 99:207-217. https://dx.doi:10.1016/j. landurbplan.2010.11.005 
Dirección Meteorológica de Chile. 2020. Informe Anual de Agua Caída. Available at https:// climatologia.meteochile.gob.cl/application/ anual/aguaCaida Anual/450005/2020 (Accessed April 27, 2020).

Franco, J.A., P. Gaspar, and F.J. Mesias. 2012. Economic analysis of scenarios for the sustainability of extensive livestock farming in Spain under the CAP. Ecological Economics 74:120-129. ecolecon.2011.12.004

García-Martínez, A., A. Bernués, and A.M. Olaizola. 2011. Simulation of mountain cattle farming system changes under diverse agricultural policies and off-farm labour scenarios. Livestock Science 137:73-86. https://dx.doi:10.1016/j.livsci.2010.10.002

Gerber, P.J., H. Steinfeld, B. Henderson, A. Mottet, C. Opio, J. Dijkman, A. Falcucci, and G. Tempio. 2013. Tackling climate change through livestock - A global assessment of emissions and mitigation opportunities. Food and Agriculture Organization of the United Nations (FAO), Rome. Available at https://www.fao.org/3/i3437e/i3437e.pdf (Accessed November 19, 2020).

Gobierno de Chile (Dirección meteorológica). 2017. Annual rainfall report (2012 and 2017). Available at https://climatologia. meteochile.gob.cl/application/anual/ aguaCaidaAnual/450005/2017 (Accessed April 27, 2020).

Gómez-Ramos, A., I. Bardají-Azcaráte, and I. Atance-Muñiz. 2006. The role of geographical labelling in inserting extensive cattle systems into beef marketing channels. Evidence from three Spanish case studies. Cahiers d'Economie et de Sociologie Rurales, INRA Editions, 78:81-99. Available at https://hal. archives-ouvertes.fr/hal-01201119 (Accessed November 12, 2020).

Hepp, C., C. Reyes, F. Elizalde, M. Tapia, P. Almonacid, A. Naguil, and P. Barattini. 2018. Calidad de carnes bovinas producidas en sistemas forrajeros de la Patagonia húmeda (Aysén). p. 59-82. En H.F. Elizalde (ed.). Desarrollo de estrategias de diferenciación de calidad de carnes rojas (bovino y ovino) en base a los recursos forrajeros de ambientes contrastantes de la zona Sur y La Patagonia de Chile. Boletín INIA No 352. Instituto de Investigaciones Agropecuarias, Coyhaique, Chile. Available at (PDF) Calidad de carnes bovinas producidas en sistemas forrajeros de la Patagonia húmeda (Aysén) (researchgate. net). (Accessed April 15, 2021).
Horcada-Ibáñez A., O. Polvillo-Polo, A. LafuenteGarcía, P. González-Redondo, A. MolinaAlcalá, and A. Luque-Moya. 2016. Beef quality of native Pajuna breed calves in two production systems. Agrociencia 50:167182. Available at https://www.researchgate. net/publication/299174218_Beef_quality_ of_native_pajuna_breed_calves_in_two_ production_systems. (Accessed January 12, 2020).

INDAP (Instituto de Desarrollo Agropecuario). MinisteRío de Agricultura de Chile. Gobierno de Chile. 2014. Available at https://www. indap.gob.cl/docs/default-source/defaultdocument-library/lineamientos-estrategicos. pdf?sfvrsn=0 (Accessed April 29, 2020).

INE (Instituto Nacional de Estadística de Chile). 2007. Censos agropecuarios. Available at https://www.ine.cl/estadisticas/economia/ agricultura-agroindustria-y-pesca/censosagropecuarios (Accessed May 25, 2021).

INE (Instituto Nacional de Estadística de Chile). 2017. Encuesta de Presupuestos Familiares. Available at https://www.ine.cl/estadisticas/ sociales/ingresos-y-gastos/encuesta-depresupuestos-familiares (Accessed April 2, 2021).

Iñiguez, L. 2011. The challenges of research and development of small ruminant production in dry areas. Small Rumin. Res. (98):12-20. https://dx.doi:10.1016/j. smallrumres.2011.03.010

Kamilaris, C., R.J. Dewhurst, A.J. Sykes, and P. Alexander. 2020. Modelling alternative management scenarios of economic and environmental sustainability of beef finishing systems. Journal of Cleaner Production 253:1-11. https://dx.doi:10.1016/j. jclepro.2019.119888

Martín-Collado D., K. Soini, A. Mäki-Tanila, M.A. Toro, and C. Díaz. 2014. Defining farmer typology to analyse the current state and development prospects of livestock breeds: The Avileña-Negra Ibérica beef cattle breed as a case study. Livest Sci. 169:137-145. https://dx.doi:10.1016/j.livsci.2014.09.003

Masera, O., M. Astier, and S. López-Ridaura. 1999. Sustentabilidad y manejo de recursos naturales. El marco de evaluación MESMIS. Grupo InterdisciplinaRío de Tecnología Rural Apropiada y Mundi-Prensa. México, D.F. 101 p. Available at https://www.researchgate.net/ publication/299870632_Sustentabilidad_y_ manejo_de_recursos_naturales_El_Marco_ de_evaluacion_MESMIS (Accessed January 19,2020 ). 
Mena, Y., J. Nahed, F.A. Ruiz, J.B. SánchezMuñoz, J.L. Ruiz-Rojas, and J.M. Castel. 2012. Evaluating mountain goat dairy systems for conversion to the organic model, using a multicriteria method. Animal 6(4):693-703. https://dx.doi:10.1017/S175173111100190X

Mena, Y., J. Ruiz-Mirazo, F.A. Ruiz, and J.M. Castel. 2016. Characterization and typification of small ruminant farms providing fuelbreak grazing services for wildfire prevention in Andalusia (Spain). Science of the Total Environment 544:211-219. https://dx.doi:10.1016/j.scitotenv.2015.11.088

Morales-Jerrett, E., J.M. Mancilla-Leytón, M. Delgado-Pertíñez, and Y. Mena. 2020. The contribution of traditional meat goat farming systems to human wellbeing and its importance for the sustainability of this livestock subsector. Sustainability 12:1181. https://www.mdpi.com/2071-1050/12/3/1181

Nahed, J., J.M. Castel, Y. Mena, and F. Caravaca. 2006. Appraisal of the sustainability of dairy goat systems in Southern Spain according to their degree of intensification. Livest. Prod. Sci. 101:10-23. https://dx.doi:10.1016/j. livprodsci.2005.08.018

Nahed, J., S. Gonzalez Pineda, D. Grande, J.R. Aguilar, B. Sánchez, J.L. Ruiz Rojas, F. Guevara-Hernandez, N. Leon Martinez, R.J. Trujillo Vazquez, and M.R. Parra Vazquez. 2018. Evaluating sustainability of conventional and organic dairy cattle production units in the Zoque Region of Chiapas, Mexico. Agroecology and Sustainable Food Systems. https:// dx.doi:10.1080/21683565.2018.1534302

Niamir-Fuller, M. 2016. Towards sustainability in the extensive and intensive livestock sectors. Hev. Sci. Tech. Off. Int. Epiz. 35(2): 371-387. https://dx.doi:10.20506/rst.35.2.2531

Reyes, C., C. Hepp, A. Naguil, and M. Monsalve. 2020. Condiciones climáticas y crecimiento de las praderas en la Patagonia Húmeda (región de Aysén). Informativo 46. INIA. Chile. Available at (PDF) Condiciones climáticas y crecimiento de las praderas en la Patagonia Húmeda . (Accessed April 15, 2021).

Rigby, D., P. Woodhouse, T. Young, and M. Burton. 2001. Constructing a farm level indicator of sustainable agricultural practice. Ecol Econ 39:463-478. https://www. njenvirothon.org/uploads/2/6/3/3/26336326/ constructing_a_farm_level_indicator.pdf
Ripoll-Bosch, R., B. Díez-Unquera, R. Ruiz, D. Villalba, E. Molina, M. Joy, A. Olaizola, and A. Bernués. 2012. An integrated sustainability assessment of Mediterranean sheep farms with different degrees of intensification. Agricultural Systems 105:46-56. https:// dx.doi:10.1016/j.agsy.2011.10.003

Ripoll-Bosch, R., M. Joy, and A. Bernués. 2014. Role of self-sufficiency, productivity and diversification on the economic sustainability of farming systems with autochthonous sheep breeds in less favoured areas in Southern Europe. Animal 8(8):1229-1237. https://dx.doi:10.1017/S1751731113000529

Ruiz, F.A., M. Vázquez, J.A. Camúñez, J.M. Castel, and Y. Mena. 2020. Characterization and challenges of livestock farming in Mediterranean protected mountain areas (Sierra Nevada, Spain). Spanish Journal of Agricultural Research 18 (1), e0601. https:// revistas.inia.es/index.php/sjar/article/ view/14288

Sarria, J.A., F.A. Ruiz, Y. Mena, and J.M. Castel. 2014. Characterization of goat production systems of the Peruvian coast. Prospects for improvement. Rev. Mex. Cienc. Pecu. 5(4):409-427. https://cienciaspecuarias. inifap.gob.mx/index.php/Pecuarias/article/ view/4014

Schwab, F., A. Calle-Collado, and R. Muñoz. 2020. Economía social y solidaria y agroecología en cooperativas de agricultura familiar en Brasil como forma de desarrollo de una agricultura sostenible. CIRIEC-España. Revista de Economía Pública, Social y Cooperativa 98:189-211. https://ojs.uv.es/index.php/ ciriecespana/article/view/14161

Stampa, K., C. Schipmann-Schwarze, and U. Hamm. 2020. Consumer perceptions, preferences, and behavior regarding pastureraised livestock products: A review. Food Quality and Preference 82:103872. https:// dx.doi:10.1016/j.foodqual.2020.103872

ten Napel, J., A.A. van der Veen, S.J. Oosting, and P.W.G. Koerkamp. 2011. A conceptual approach to design livestock production systems for robustness to enhance sustainability. Livest Sci 139:150-160. https:// dx.doi:10.1016/j.livsci.2011.03.007

Tessema, W.K., P.T.M. Ingenbleek, and H.C.M. van Triip. 2014. Pastoralism, sustainability, and marketing. A review. Agron. Sustain. Dev. 34:75-92. https://hal.archives-ouvertes. $\mathrm{fr} / \mathrm{hal}-01234790$ 
Toro-Mujica, P., R. Vera, E. Vargas-Bello-Pérez, P. Pinedo, and F. Bas. 2019. Trends and Drivers of Change of Pastoral Beef Production Systems in a Mediterranean-Temperate Climate Zone of Chile. Animals 9:1135. https://www.ncbi.nlm.nih.gov/pmc/articles/ PMC6941165/pdf/animals-09-01135.pdf

Valdivieso Pérez, I.A., J. Nahed Toral, A.T. Piñeiro Vázquez, F. Guevara Hernández, G. Jiménez Ferrer, D. Grande Cano. 2019. Potential for organic conversion and energy efficiency of conventional livestock production in a humid tropical region of Mexico. Journal of Cleaner Production 241, 118354 https:// www.sciencedirect.com/science/article/abs/ pii/S095965261933224X
Werner, M., C. Hepp, C. Soto, P. Gallardo, H. Bustamante, and C. Gallo. 2013. Effects of a long distance transport and subsequent recovery in recently weaned crossbred beef calves in Southern Chile. Livestock Science 152:42-46. https://dx.doi:10.1016/j. livsci.2012.12.007 